\title{
Growing reaction to ozone hole in Soviet Union
}

\section{London}

Sovetskaya Rossiya, the newspaper that two years ago led the campaign to halt the southward division of the Siberian rivers, has now turned its attention to ozone holes. In an appeal to the USSR State Committee for the Protection of Nature, it called for a "ruthless struggle against those who violate ecological laws". A recent computerized study, it reported, had observed more than 50 cases of reduction in the concentration of ozone above major cities in the European part of the Soviet Union, including Moscow.

Sovetskaya Rossiya's concern differs considerably from the attitude to ozone holes over the past few months of the official Soviet news agency TASS, which has on several occasions suggested that ozone holes are a puzzling, but not anthropogenic phenomenon. In April, reporting that a team at the Soviet Molodezhnaya station in Enderby Land would be spending the forthcoming southern winter in carrying out the first-ever "comprehensive" ozone monitoring programme, it cited one of the team's leaders, Dr Aleksandra Chetverikov of the Volkov geophysical observatory in Leningrad, as saying that data gathered at Molodezhnaya during the summer of 1987-88 may refute the "ozone hole" theory.

A few weeks later, TASS produced a Georgian scientist, Dr Teimuraz Toroshelidze, who declared that ozone holes hold no threat of disastrous consequences for mankind; they are a normal natural phenomenon, resulting from turbulent flow round a high obstacle such as a mountain or the Antarctic plateau. Fluctuations of ozone concentration are frequent over the Caucasus, he said, and are caused by strong winds above $5 \mathrm{~km}$ over the northwestern part of the range. Above the Abastumani astrophysical observatory, where Toroshelidze works, an increase of wind velocity by $10 \mathrm{~m}$ per second reduces stratospheric ozone content by some 5 per cent, he said.

Even those scientists who have stressed the ultraviolet hazard of ozone holes, such as Dr Nikolai Elanskii of the Institute of Atmospheric Physics of the Soviet Academy of Sciences, seem to take an ambivalent stance in TASS interviews. Although Elanskii noted that the Soviet Union had signed the 1985 Vienna Convention on the Ozone Layer and the 1987 Montreal protocol on ozone-destroying substances, and by 1993 will have switched from freons to ozone-friendly hydrocarbons for domestic aerosols, he emphasized that the beginning of "intensive ozone destruction" coincided with the 1982 eruption of El Chichon, implying that aerosols from the Mexican volcano were chiefly to blame.

Soviet scientists are eager to cooperate with their western colleagues in studying the phenomenon. According to Dr Igor $\mathrm{Karol}$, head of the laboratory of climate theory at the Main Geophysical Observatory of the USSR in Leningrad, recent Soviet proposals for cooperation include a chain of monitoring stations (one in the Canadian arctic archipelago, one on Cape Barrow, one on Wrangel Island), simultaneous Soviet, Canadian and American trans-Arctic flights, and - most interesting - the 'internationalization' of one of the Soviet drifting icefloe Arctic stations to include Canadian and US teams in 1989 or 1990.

Vera Rich

- The results of the US expedition during the 1987-88 Antarctic summer, in which ozone concentration and atmospheric chemistry were mapped over the whole region, convinced even the manufacturers of chlorofluorocarbons that their products were implicated in polar ozone destruction. No clear indications of ozone loss over cities in the United States are apparent from satellite measurements, but according to Mark Schoeberl, of the NASA/Goddard Space Flight Center, local ozone concentrations fluctuate daily as weather conditions change, and a buildup of sulphur dioxide from urban pollution can look to the satellite like a stratospheric ozone loss.

David Lindley

\section{Tucson}

CONGRESs, not regional wildlife biologists, will decide the best way to manage the habitat of an endangered squirrel if the University of Arizona and its congressional delegation have their way.

The 200 or so extant Mount Graham red squirrels, Tamiasciurus hudsonicus grahamensis, live on Mount Graham, an 11,000 -foot-high peak in southern Arizona that is the proposed site for a University of Arizona observatory. Astronomers want to put seven telescopes, including the Columbus Project and the Max Planck submillimetre telescope, on the mountain and have spent more than a million dollars evaluating, planning and lobbying for the facility.

Frustrated at waiting for federal agencies to complete their assessment of the impact of land use on the squirrel population, and concerned that telescopes would be located elsewhere if construction were delayed any longer, the university asked its congressmen to designate the mountaintop an astrophysical reserve exempt from the assessment process.

Attempts to attach a rider to federal legislation before the recess on 12 August failed, but US Fish and Wildlife and Forest Service administrators in Washington are working with Arizona congressmen on the proposed legislation.

In July, the US Fish and Wildlife Service rejected the proposal to build seven telescopes on Mt Graham's twin peaks, but offered three alternative plans to the university and the National Forest Service, which has the final say on land use (see Nature 334, 188; 1988). The university accepted an option to build three telescopes on Emerald Peak alone, but wanted additional land reserved for four more telescopes, anticipating that the objections could eventually be overcome The university also objected to a demand that an old access road, through 'squirrel country', should be closed before a new one was built, as that would have delayed the start of construction until next year.

Complaining that it had already been waiting for four and a half years, the university asked the Forest Service to make a final decision by the end of August. Laurel L. Wilkening, vicepresident of research at the university, told the Forest Service that one telescope had already been lost, and another (the Max Planck telescope) will soon be lost. "We cannot pursue any additional processes that would require further delay", she said.

But the Forest Service said a final decision could not be made for several months. Consultation with the US Fish and Wildlife Service would be necessary as well as public discussion and a new environmental assessment of the alternative Emerald Peak plan.

The university does not want to wait and has tried to enlist congressional help. Arizona senators John McCain (Republican) and Dennis DeConcini (Democrat) tried on 4 August to attach a rider to the Senate dire emergency supplemental appropriations bill which would have allowed immediate construction of three telescopes and land for seven. The four other telescopes were to be built after consultation with the US Fish and Wildlife Service. Although the language of the rider was never finalized, Randall A. Smith, a biologist with the National Forest Service said that the legislative actions "are taking the final decision away from the Forest Service and they are taking away from the public the right to comment". Elizabeth Pennisi 